Department of Business Administration

UZH Business Working Paper Series

Working Paper No. 361

Human resource management and radical innovation.

A fuzzy-set QCA of US multinationals in Germany, Switzerland, and the UK

Uschi Backes-Gellner, Marlies Kluike, Kerstin Pull, Martin Schneider and Silvia Teuber

December 2015

University of Zurich, Plattenstrasse 14, CH-8053 Zurich, http://www.business.uzh.ch/forschung/wps.html 
UZH Business Working Paper Series

\title{
Contact Details
}

\author{
Prof. Dr. Uschi Backes-Gellner (corresponding author) \\ University of Zurich \\ Department of Business Adminstration \\ Plattenstrasse 14., CH-8032 Zurich, Switzerland \\ backes-gellner@business.uzh.ch \\ Tel.: +41446344281 \\ Fax.: +41446344370
}

\author{
Dr. Marlies Kluike
}

University of Tübingen

Department of Human Resource Management and Organization

marlies.kluike@uni-tuebingen.de 


\title{
Prof. Dr. Kerstin Pull
}

University of Tübingen

Department of Human Resource Management and Organization kerstin.pull@uni-tuebingen.de

\section{Prof. Dr. Martin R. Schneider}

University of Paderborn

Department of Business Administration and Economics

martin.schneider@upb.de

\author{
Dr. Silvia Teuber \\ University of Zurich
}

Department of Business Administration and Economics 
Published in Journal of Business Economics (2016).

The final publication is available at Springer via http://dx.doi.org/10.1007/s11573-015-0803-3.

\title{
Human resource management and radical innovation. A fuzzy-set QCA of US multinationals in Germany, Switzerland, and the UK
}

\author{
by
}

Uschi Backes-Gellner, Marlies Kluike, Kerstin Pull, Martin Schneider, Silvia Teuber ${ }^{\dagger}$

\begin{abstract}
This paper explores, based on the varieties-of-capitalism approach, configurations of key human resource management practices that explain radical innovation in subsidiaries. A fuzzy-set qualitative comparative analysis is conducted with data for 69 subsidiaries of US-based MNEs in Germany, Switzerland, and the UK. Contrary to the implications of the varieties-of-capitalism literature, combining numerical flexibility and employing a high share of academics does not necessarily achieve radical innovation. Various paths to radical innovation exist, and most of them involve functional flexibility. Overall, the findings emphasize the strategic discretion MNEs have, and accentuate that functional flexibility is a key HR practice to achieve radical innovation across differing varieties of capitalism countries.
\end{abstract}

Keywords: Functional flexibility, numerical flexibility, radical innovation, radical change, varieties of capitalism, qualitative comparative analysis

\footnotetext{
* This study was funded by research grants from the German National Science Foundation and the Swiss National Science Foundation; Silvia Teuber also received a mobility grant of the Swiss National Science Foundation for a research stay at Harvard University and was partly funded by the Swiss Leading House on Economics of Education, Firm Behavior and Training Policies.

${ }^{+}$Prof. Dr. Uschi Backes-Gellner, University of Zurich, Department of Business Administration, Plattenstrasse 14, 8032 Zurich, Switzerland, Phone +41 (0) 4463 44281, Fax +41 (0) 4463 44370, Email: backes-gellner@business.uzh.ch (corresponding author); Dr. Marlies Kluike, University of Tuebingen, Department of Human Resource Management and Organization; Prof. Dr. Kerstin Pull, Professor at the University of Tuebingen, Department of Human Resource Management and Organization, Prof. Dr. Martin R. Schneider, University of Paderborn, Department of Business Administration and Economics, Dr. Silvia Teuber, University of Zurich, Department of Business Administration.
} 


\section{Introduction}

In this paper, we seek to shed light on how multinational enterprises (MNEs) achieve radical innovation in their subsidiaries through a set of key HR practices: by employing generally-skilled academics, by adapting staff levels to company needs (numerical flexibility), and/or by assigning multiple tasks to employees (functional flexibility). Numerical and functional flexibility have long been discussed as the key HR categories explaining the adaptability, innovation, and ambidexterity of companies (Atkinson 1984; Valverde, Tregaskis and Brewster 2000; Kalleberg 2001; Cappelli and Neumark 2004; Zhou, Dekker and Kleinknecht 2011; Bouncken, Lehmann and Ratzmann 2013; Flicking, GruberMücker and Fiedler 2013). They are sometimes interpreted as alternative, incompatible ways in which companies can bring about learning and change (Giannetti and Madia 2013; Wilkens, Ruiner and Küpper 2013). Further, the extent to which companies employ generally-skilled academic personnel has also been argued to be a chief factor accounting for companies' ability to learn (Jensen, Johnson, Lorenz and Lundvall 2007) and to implement radical innovation (Hall and Soskice 2001).

We focus on HR practices because sourcing and developing individual skills often represents the bottleneck for MNEs to achieve radical innovation in local subsidiaries. MNEs are able to mobilize most other resources on an international scale: Financial resources travel across borders, and standardized production technology can be deployed easily. But workers are much less mobile. Hence, to a considerable extent subsidiaries depend on local employees and the skills they supply. Furthermore, institutions - in particular, national regulations of labor markets and skill creation - influence the way in which companies may achieve functional and numerical flexibility. We focus on the subsidiary rather than the company as the level of analysis because the innovation process is context-specific and conducted at the level of local subsidiaries (Ciabuschi, Forsgren and Guy 2011).

In order to derive a theoretical framework, we borrow from the varieties-of-capitalism (VoC) approach by Hall \& Soskice (2001). The VoC focuses on how institutional arrangements influence a company's capability to organize 'radical innovation' in comparison to more 'incremental innovation'. The VoC more generally helps to understand the behavior of MNEs (Jackson and Deeg 2008) and has been a theoretical benchmark for studies in international business (Jackson and Miyajima 2007; Herrmann and Peine 2011; Witcher and Chau 2012), international HRM (Brewster, Wood and Brookes; Iseke and Schneider 2012), comparative industrial relations (Bamber, Lansbury and Wailes 2011), and innovation theory (Lazonick 2010; Allen 2013).

According to the VoC approach numerical flexibility and the employment of generally-skilled academics are supported by an institutional framework called 'liberal market economies' (LMEs): by lax employment protection legislation and a sturdy supply of well-trained university graduates (Hall \& Soskice 2001). The USA is the main example of an LME. Therefore, it has been argued that US companies often hold an institutionally grounded competitive advantage in goods and services involving 
radical innovation or change (Porter 1990; Hall and Soskice 2001; Bassanini and Ernst 2002; Schneider, Schulze-Bentrop and Paunescu 2010). When US MNEs try to accomplish radical innovation in their subsidiaries, however, they may face institutional environments that are allegedly less favorable to radical innovation along these lines. In particular, 'coordinated market economies' (CMEs) in Europe such as Germany may be less conducive to radical changes. Then again, it has been shown that some CMEs such as Germany hold comparative advantages in sectors involving radical innovation (e.g. Schneider and Paunescu 2013).

Exploring HR practices that lead to radical innovation therefore involves a number of particular issues that are related to the widespread discussion of home and host country effects. While 'home country effect' refers to a situation where the subsidiary of an MNE applies practices 'from home'; 'host country effects' refer to a situation where the subsidiary of an MNE adapts to the local practices of the host country. US-MNEs that apply their home country strategy which is based on the institutions of a liberal market economy, may achieve radical innovation (this is called the home country effect). This would imply that they combine numerical flexibility, the employment of academics and a high-techstrategy in order to achieve radical innovation - irrespective of where they are located. Conversely, US-MNES that adapt to local practices and use CME-specific combinations of HR strategies when situated in a CME host country may also achieve radical innovation (this is called host country effect).

To explore the HR practices leading to radical innovation, we present findings from a survey on 69 subsidiaries of US-based MNEs in Germany, the UK, and Switzerland. The host countries include a CME (Germany) and an LME (UK) along with a hybrid economy, i.e. an economy with a mixture of institutions from LMEs and CMEs (Switzerland). Switzerland particularly combines a strong apprenticeship system typical of a CME with permissive employment protection typical of an LME.

Applying a fuzzy-set qualitative comparative analysis (fs/QCA) (Ragin 2000, 2008), we show various causal paths leading to radical innovation in a US-subsidiary. The findings are interesting yet puzzling. Contrary to implications of the $\mathrm{VoC}$ approach, various causal paths sufficiently explain radical innovation. These do neither reflect pure US home country effects nor host country effects. Neither do US subsidiaries in UK, Germany and Switzerland generally use the LME-typical combination of HR strategies leading to radical innovation (home country effect) nor do they generally adapt to the typical host-country combination of HR strategies (host country effect). Interestingly, most causal paths leading to radical innovation involve functional flexibility (but not numerical flexibility) and the absence of employing large shares of academic personnel. Our findings are at odds with the idea of US MNEs exporting their business model. Rather, the causal paths are diverse and are a reflection of subsidiaries' leeway in designing their HR practices to achieve radical innovation.

Our paper provides two main contributions to the previous literature. It firstly speaks to the growing literature that applies the VoC approach to international business (Jackson 2005; Schneider et al. 
2010). However, it is to our knowledge the first firm-level analysis referring to the VoC approach that (a) includes cases from multiple industries, (b) rests on a larger sample, and (c) applies fs/QCA. Until recently, industry-based analyses have been suggested to uncover links between institutional capital and innovative performance (Kristensen and Morgan 2012; Allen 2013) - a strategy that necessarily restricts the number of cases for analysis. The method of fs/QCA, though increasingly important to uncover complex causality in business studies (Fiss 2007, 2011; Crilly 2010; García-Castro, Aguilera and Ariño 2013), has been applied to ideas of the VoC only with country-level data so far (Schneider et al. 2010; Allen and Aldred 2011). In our findings, various combinations of HR practices are linked to radical innovation as measured by the importance and the frequency of core changes in products and services. This resonates with warnings that the VoC should not equate countries with companies (Allen 2004; Crouch 2005), and it supports the view that there are more ways to achieve radical change than the VoC approach suggests (Jensen et al. 2007).

Secondly, our paper also contributes to the institutional theory of MNEs (Henisz and Swaminathan 2008; Jackson and Deeg 2008; Heidenreich 2012). However, so far the institutional literature that pertains to our questions has focused primarily on how institutional arrangements including labor market regulation attracts or deters foreign direct investment (Henisz 2000; Witt and Lewin 2007; Pajunen 2008; Pull 2008) and on how institutional arrangements encourage or inhibit the transfer of HR practices within MNEs (Schmitt and Sadowski2003; Fenton-O'Creevy, Gooderham and Nordhaug 2007; Farndale, Brewster and Poutsma 2008; Parry, Dickmann and Morley 2008; Iseke and Schneider 2012). By contrast, we focus on how subsidiaries - after having selected into a certain location - achieve radical change through the choice of a set of HR practices. Our findings suggest that MNEs hold considerable leeway in designing their HR practices in order to achieve radical change. The findings also suggest that functional flexibility is a key HR practice for radical innovation across differing varieties of capitalism.

\section{Theoretical considerations}

Our study is guided by two alternative propositions. They are developed from engaging the VoC literature with the literature on work organization and learning (Lorenz and Valeyre 2005; Arundel, Lorenz, Lundvall and Valeyre 2007; Jensen et al. 2007).

\subsection{An LME path to radical innovation}

The VoC approach makes two important claims that suggest a home country effect when it comes to the question how US subsidiaries will try to achieve radical innovation. The first claim is that radical change often involves science-based innovations and a strongly fluctuating demand for workers. Therefore, numerical flexibility and a high share of academic personnel are likely to be connected to radical innovation. Academic personnel is important because scientifically trained personnel brings in 
outside knowledge, thereby increasing the absorptive capacity of the firm and permitting radical changes in products, processes, business concepts, and technologies (Estevez-Abe, Iversen and Soskice 2001; Hall and Soskice 2001; Minbaeva, Pedersen, Björkman, Fey and Park 2003; Casper 2007; Herrmann and Peine 2011). The resulting swings in business activity and skill needs, in turn, call for numerical flexibility, the frequent hiring and firing of workers. The second claim is that the US institutional framework is particularly conducive to numerical flexibility and hiring academic personnel and that, therefore, US companies often engage in these HR practices.

The two claims appear to suggest a home country effect in European subsidiaries of US MNEs. When they try to achieve radical innovation, they will engage in those practices that work at home and that are appropriate for radical innovation and learning. However, these practices will not be connected to radical innovation unless it is part of a company's strategy. Therefore, an important additional condition, or contingency, is a company strategy involving strong $R \& D$ or high tech. Consistent with that idea, accounts of innovation at company level have detected a science, technology, and innovation (STI) mode of learning (Jensen et al. 2007). It is geared towards explicit, science-based knowledge. It calls for the employment of academics and strong $R \& D$. The expectation of a home country effect is further supported by accounts of US MNEs. They are considered as dominant in international business (Pudelko and Harzing 2007), and their business practices are therefore readily adopted in host countries. Furthermore, US MNEs seem to be prone to exporting their practices abroad even into strongly regulated economies such as Germany (Iseke and Schneider 2012). Overall, these considerations suggest a host country effect:

A combination of (a) numerical flexibility, $(b)$ the employment of a high share of academic personnel and (c) a high tech strategy will explain radical innovation among subsidiaries of US MNEs, irrespective of where they are located (Proposition 1 - Home country effect).

\subsection{A CME path to radical innovation}

A number of considerations give rise to an additional proposition, which may result in US subsidiaries adapting to host-country specific paths to radical innovation. Dichotomies such as radical versus incremental innovation are common in the literature to describe different natures of the innovation process (Latzer 2009), and a one-to-one correspondence of innovation type to type of flexibility is suggested by the VoC approach. But in-depth analyses on links between HR practices and indicators of innovation in Europe show that radical innovation may be achieved not only through employing academics and numerical flexibility. Rather, radical change may also be achieved by an alternative model of doing, using, and interacting (DUI) (Jensen et al. 2007). In terms of HRM, the DUI mode of learning is based on functional flexibility, the continuous updating of knowledge achieved through worker discretion. In a related approach a 'learning model' involving functional flexibility has been found to be linked to strong radical change and innovative success (Arundel et al. 2007). 
That literature also states, similar to the VoC approach, that institutional frameworks support the styles of learning differently (Lorenz and Valeyre 2005; Lorenz 2011). It was found in particular: ‘... in nations where work is organized to support high levels of discretion in solving complex problems firms tend to be more active in terms of innovations developed through their in-house creative efforts. In countries where learning and problem solving on the job are more constrained, and little discretion is left to the employee, firms tend to engage in a supplier-dominated innovation strategy. Their technological renewal depends more on the absorption of innovations developed elsewhere.' (Arundel et al. 2007: 1175)

Given more than one causal path to radical innovation and given the strong institutional differences between European economies, host country effects become a more likely expectation than home country effects. In particular, in Germany as a CME (Schneider and Paunescu 2012) with a strong proportion of companies following the learning model (Arundel et al. 2007), subsidiaries of US MNEs may diverge from the home country model and may instead more commonly adopt functional flexibility in Germany. They may then also refrain from employing a high share of academic personnel. Conversely, the UK is more similar to the USA. It is an LME (Schneider and Paunescu 2012), and a high proportion of companies follow a lean production model geared towards numerical flexibility (Arundel et al. 2007). Therefore, subsidiaries of US MNEs should implement numerical flexibility in the UK, but functional flexibility in Germany. Switzerland is an interesting intermediate case. Though it has been discussed as a CME similar to Germany, it is in fact a hybrid economy with a labor market that allows for numerical flexibility and a vocational training system similar to Germany (Kluike and Pull 2013, Teuber 2012). Given these institutions, subsidiaries in Switzerland may follow either the German or the British pattern.

In the first proposition it was argued that numerical flexibility and academic personnel will be linked to radical innovation in particular when combined with a high tech strategy. There is a similar contingency with functional flexibility. It has been argued that learning based on functional flexibility will often be used in companies in conjunction with production flexibility, i.e., the possibility to put assets in place to different uses (Pull 2003). Though from a theoretical perspective the two types of flexibility are clearly distinct, empirically they are expected to be mutually supportive or complementary in achieving radical innovation. It is in subsidiaries with production flexibility that functional flexibility will contribute to radical innovation. As such a combination is most common in the German CME environment, we posit a particular host country effect for Germany:

A combination of (a) functional flexibility, (b) a low share of academic personnel and (c) production flexibility will explain radical innovation among subsidiaries of US MNEs in Germany (Proposition 2 - Host country effect). 


\subsection{Summary of Propositions}

To sum up, we have two propositions that can be visualized as shown in Figure 1. Given our theoretical considerations there are two paths to radical innovation: one combining numerical flexibility, a high share of academic personnel and a high tech strategy (shaded area in Figure 1), and another one combining functional flexibility, a low share of academic personnel and production flexibility (nonshaded area in Figure 1).

Proposition 1 (home country effect) claims that some subsidiaries of US MNEs will achieve radical innovation along the shaded path - irrespective of where the subsidiary is located.

Proposition 2 (host country effect) states that in Germany an observed path to radical innovation of US NMEs will also be the non-shaded path.

Insert Figure 1 about here

This means that our theoretical considerations are of a configurational type (Fiss 2007; Meyer et al. 1993): They state the interplay of various factors in explaining radical innovation, in contrast to a theory that posits marginal effects of single factors on radical innovation. Given the number of factors we study, our two propositions are very specific. This is because they refer to a limited number of combinations although many other combinations are also logically possible (such as for example functional flexibility * numerical flexibility * the absence of production flexibility). At the same time, our two propositions are not mutually exclusive. For example, there may be some subsidiaries whose path to radical innovation is based on the LME model, thus supporting Proposition 1. Other subsidiaries in Germany may show a path conforming to Proposition 2. In other words, our theoretical considerations involve equifinality (Fiss 2007; Gresov and Drazin 1997; Doty et al. 1993).

\section{Data and methods}

\subsection{Sample}

We used data on 69 US-subsidiaries located in Germany, Switzerland, and the UK. The data set was collected from 2010 to 2012 with the help of a survey sent to 1,500 randomly drawn high-level subsidiary managers from companies of different sectors (500 per country) about which we obtained relevant background information from the Amadeus database (Bureau van Dijk 2009). As the response rates were at the beginning very different for the German-speaking countries in comparison to the UK, we started an additional round of data-collection for the UK to have comparable numbers of companies in all three countries. Such a strategy is possible because the method we apply, the fs/QCA-method, does not strive for representativeness as will be explained in the next section. Overall, 99 replies were ob- 
tained. After deleting the observations with missing values and those subsidiaries employing fewer than 10 employees, 69 cased remained, with 21 in the UK, 26 in Switzerland, and 22 in Germany.

\subsection{Method}

Instead of using typical regression analyses, we apply fuzzy-set qualitative comparative analysis (fs/QCA) (Ragin 1987, 2000, 2008; Rihoux and Ragin 2009; Schneider and Wagemann 2012). The main reason for using fs/QCA is the configurational nature of our propositions (Fiss 2007). In linear models, each of a number of factors is seen as contributing independently and cumulatively to a certain dependent variable. In configurational methods, only combinations of factors are assumed to explain a certain result. We predict, for example, that a combination of numerical flexibility, the employment of a high share of academic personnel and a high tech strategy will explain radical innovation. The elements of this combination do not simply add up, but interact in synergistic ways. It is exactly for this type of configurational theory with complex causality that fs/QCA is suggested as more appropriate than regression analysis (Fiss 2007). The better fit of the method with our data can be further illustrated with two important points. First, our theory implies equifinality, i.e. various combinations may lead to the same outcome (Fiss 2007; Gresov and Drazin 1997; Doty et al. 1993). We imply in Proposition 2 that subsidiaries of US MNES in Germany will achieve radical innovation through a path that differs from that of subsidiaries in the UK. The fs/QCA method detects multiple paths by exploring sufficient combinations of conditions. A condition is sufficient when it always leads to an outcome, but sufficiency does not exclude that certain other conditions may also lead to the same outcome. Second, configurational theory implies that causal factors may influence an outcome asymmetrically (Doty et al. 1993; (Greckhamer, Misangyi, Elms and Lacey 2008). A high share of academic personnel contributes to radical innovation when combined with numerical flexibility and a high tech strategy; when combined with functional flexibility and production flexibility, however, a low share of academic personnel contributes to radical innovation. In a regression analysis, where average effects are estimated, these asymmetric effects would cancel out. In fs/QCA, however, it is possible that the inclusion of a causal factor may explain the outcome in one combination while in another combination the negation (non-existence) of the factor may explain the outcome.

Furthermore, it is important to note that the method is not based on the assumption of a randomly drawn sample and is not focused on estimating average effects (Fiss 2007). Rather, it focuses on exploring in an inductive way which combinations of causal factors are related to an outcome in an observed case sample. Therefore, the case-study logic of our sample does not harm the validity of our findings produced by fs/QCA. Fs/QCA does not apply statistics but set theory and logic. The application of the method involves three major steps.

In a first step, the measures for the outcome (in conventional language the 'dependent variable') and the causal factors (in conventional language the 'explanatory variables') are calibrated into set mem- 
bership scores. Fs/QCA allows fuzzy membership scores ranging from 0 to 1 . This is appropriate when the raw values of the outcome and the causal conditions are on a continuous scale. Part of the analysis involves crisp set membership values. Here all fuzzy scores below 0.5 are transformed to 0 , and all fuzzy scores above 0.5 are transformed to 1 . As a result, various cases with differing fuzzy scores are lumped together into one ideal type.

In a second step, to prepare the 'analysis of sufficient conditions', all ideal types are reported in a truth table. Given k number of conditions, there will be 2 to the power of k rows. Each row represents an ideal type. Not all of the ideal types that are logically possible will actually be observed in the data; this fact is termed 'limited diversity' (Ragin 2000). A particular ideal type is considered as strictly sufficient for the outcome when all cases represented in the ideal type also show the presence of the outcome. Most often this strict rule will not hold. Instead, there are a few cases represented in the ideal type for which the outcome is absent. In our case, for example, 18 subsidiaries combining numerical flexibility with a high share of academic personnel and a high tech strategy show radical innovation but two subsidiaries with the same combination of conditions do not. We would still conclude that this ideal is a sufficient condition for radical innovation even though this pattern is not consistent for all cases. For this situation, a consistency score is used. It gives a quantitative threshold that allows us to call certain combinations of conditions 'sufficient".

As a third step of the analysis, the truth table rows are simplified by algorithms based on Boolean algebra (Ragin 2006, 2008). The main result of the analysis consists of one or a number of causal paths. Each path consists of one or various single conditions that jointly explain the outcome. How many causal paths and which condition each path includes evolves from the case comparisons which the socalled truth table algorithm conducts.

\subsection{Measures}

Outcome Measure: To measure our outcome, radical innovation, we use a measure that reflects the importance and the frequency of core changes in products and services. We asked the subsidiary companies to specify the degree to which they undergo core changes and the frequency with which these changes happen. Firstly, subsidiaries have to state on a 5-point Likert-scale whether they '1: strongly disagree' or '5: strongly agree' with the statement 'The subsidiary business undergoes core changes (e.g. next generation products/services) from time to time'. Secondly, subsidiaries have to estimate how often they encounter such core business changes. Three categories were possible: every 1-3 years, 4-6 years, and 7 or more years.

Our outcome variable 'radical change' was calibrated in a way that it takes a value of ' 1 ' (meaning 'full membership') when the subsidiary strongly agrees that it undergoes core changes from time to time (Likert values of 4 or 5) and the frequency of changes is within 1-3 years. The outcome takes a 
value of ' 0 ' (meaning 'full non-membership') when the subsidiary does not strongly agree that it undergoes core changes from time to time (Likert values of 1, 2 or 3 ) and the frequency of changes is within 7 or more years. Hence, information on both the incidence and on the frequency of core changes was used to construct set membership scores (see also Table 1).

Insert Table 1 about here

Causal conditions: The share of academic personnel was measured as the percentage of university graduates in the subsidiary ('What is the current approximate share of staff with a university degree as their highest qualification?'). Numerical flexibility was measured using a 5-point Likert-scale indicating the frequency of staff adjustments ('Staff numbers are often adjusted according to business need', from 1 'strongly disagree' to 5 'strongly agree'). Functional flexibility was measured using a 5-point Likert-scale indicating the degree of multi-tasking ('Most staff are assigned a broad variety of tasks', from 1 'strongly disagree' to 5 'strongly agree'). A high tech strategy was measured on a 5-point Likert-scale indicating whether the main products or services belong to high technology ('Our main business driving products/services belong to high-tech', from 1 'strongly disagree' to 5 'strongly agree'). Production flexibility was measured on a 5-point Likert-scale indicating how switchable assets are ('Assets and components used could easily be switched to another use (e.g., new products/services)', from 1 'strongly disagree' to 5 'strongly agree').

Insert Table 2 about here

The fs/QCA method involves the calibration of raw values into fuzzy-set membership scores. To do so, three threshold values need to be determined by the researcher in a meaningful way. The upper value denotes that cases with this or higher values are considered to be fully in the set, implying for example the complete presence of radical innovation. The lower bound denotes that cases with this or lower values are fully out of the set, implying for example the complete absence of radical innovation. The cross-over point denotes the raw value with maximum ambiguity: the case is neither in nor out of the set, radical innovation is neither present nor absent. It is recommended that the cross-over value is not attached to observed cases to avoid the loss of observations in the analysis. To calibrate our variables that use Likert-type scales finding these thresholds is straightforward because one interval scale is transformed into another one through the so-called direct method (Fiss 2011; Ragin 2008). When calibrating the only continuous variable, i.e. the share of academic personnel, we also use an established method, i.e. the so called log odds method which attaches membership scores to raw values based on the three anchors and following a distribution (Ragin 2008). In addition, as shown by Schneider and Wagemann (2012) the findings of fs/QCA are relatively robust with respect to minor changes in the calibrations (Schneider and Wagemann 2012). The results of calibrating our variables according to 
these two standard procedures are as follows.

The 5-point scales for numerical flexibility, production flexibility, and high-tech strategy were calibrated by coding membership as fully in for a response of 5 , and fully out for a response of 1 . The crossover point was the middle of the scale (3). Since analyzing fuzzy-set values of exactly 0.5 is not recommended (Ragin 2008), we followed the approach suggested by Fiss (2011) and subtracted a constant of 0.001 to the causal conditions with the value of 0.5 . As functional flexibility includes only answers from 2 to 5 , we calibrated the crossover point as 3.5, and membership as fully out for a response of 2. For the share of academic personnel, we defined a share of over $90 \%$ of university graduates as fully in, and a share of less than $10 \%$ of university graduates as fully out. The crossover point was at $50 \%$ (Table 2).

\section{Findings}

\subsection{Main analysis}

Table 3 contains the main findings of the fs/QCA: the various causal paths that are found to be sufficient explanations for radical innovation (in addition, complete results are summarized in Appendix A1). Each column of Table 3 describes a path consisting of combinations of causal conditions. As suggested by Ragin and Fiss (2008), we denote the presence of a condition by a $\bullet$, and the absence of a condition by $\mathrm{a} \otimes$. A blank implies that it is irrelevant whether the condition is present or absent. For example, causal path 'I' should be read as follows: A combination of 'functional flexibility', a 'high tech strategy' and the absence of 'production flexibility' go together with radical innovation. The irrelevance of the remaining two conditions implies that causal path 'I' contains cases with and without a high share of academic personnel, as well as with and without numerical flexibility, i.e. these two factors do not make a difference in this path.

Insert Table 3 about here

Note that path 'I' is only a sufficient condition, but it is not necessary to reach radical innovation. Four other paths to radical innovation evolve from the data (equifinality). Path 'I' includes 16 cases.

The remaining causal paths can be characterized along similar lines. Path II consists of subsidiaries with a high tech strategy that combine functional flexibility with a low share of academic personnel. Hence it overlaps substantially with Path I. Path II includes 11 ideal type cases. Path III consists of subsidiaries that are low on production flexibility and that combine functional flexibility with the absence of numerical flexibility and a low share of academic personnel. It covers five ideal type cases. Path IV consists of subsidiaries with high production flexibility that combine functional flexibility 
with numerical flexibility and a low share of academic personnel. It covers only two ideal type cases. Finally, Path V consists of subsidiaries with a high tech strategy and high production flexibility that combine the absence of functional flexibility with the absence of numerical flexibility and a high share of academic personnel. Though it only covers two ideal type cases, Path V is interesting: It is the only path which features a high share of academic personnel, the factor that was considered to be most important by the VoC.

Thus, taken together our findings provide only very weak support for Proposition 1, which was derived from the VoC. For ease of comparison, we have inserted in the last columns of Table 3 the theoretical causal paths implied by our propositions. There is only one causal path involving a high share of academic personnel (Path V), only one path involving numerical flexibility (path IV), and no path that combines the two. Path V combines academic personnel with high tech, thus giving some limited support for implications of Proposition 1. But Path V also features the absence of numerical flexibility, which is at odds with a key implication of the VoC approach and Proposition 1. Furthermore, in Path IV numerical flexibility is not combined with high tech or numerical flexibility, but with functional flexibility and production flexibility, thus representing a hybrid solution.

Proposition 2, which suggests a host country effect for subsidiaries in Germany, does not find strong support either. For all but one causal path, ideal type cases are found in all three host countries. The only exception is Path V, for which no ideal type from Germany was observed. But that path only covers one ideal type case each in Switzerland and the UK. Hence, no host country effect is visible. The solutions also do not give strong support for HR practices being contingent on production flexibility. Path IV combines functional flexibility with production flexibility, in line with Proposition 2, but it also involves numerical flexibility, which is at odds with Proposition 2. It is a hybrid causal path.

Our findings, however, give rise to a revised version of Proposition 2. The causal paths involve many HR practices that deviate from the US home country. Four paths (I, II, III, and IV) include functional flexibility, three paths (II, III, and IV) include the absence of a high share of academic personnel, and two paths (III and V) are distinctive for the absence of numerical flexibility. Though the causal paths are heterogeneous, they share - with the exceptions of some aspects of paths IV and V - a negation of the US home country model. Instead they appear to reflect at least to some extent the 'learning model' found in many European companies. It involves functional flexibility but still achieves radical change. Since that pattern is found across the three host countries including the UK, it clearly contradicts Proposition 1, the idea of a strong home country effect. It is not compatible with the Germany-specific host country effect posited in Proposition 2 but points to a revised host country effect: the existence of various causal paths involving the European learning model suggested by Arundel (2007). A recent study based on a more in-depth analysis of a representative Swiss data set by Meuer/Rupietta/BackesGellner (2015) also points in the direction of various causal paths within one country which seem to be the result of the an interplay of different layers of co-existing innovation systems. 


\subsection{Robustness checks}

To check the robustness of findings, we also conducted a sufficiency analysis with the negation of radical change as outcome (Table A2 in appendix). This procedure is recommended because it is technically possible that combinations of conditions explaining an outcome also explain the negation of the outcome. Such ambiguous combinations should not be interpreted as sufficient solutions. As the analysis of negation shows, our data are not confronted with this problem. In particular, the absence of radical change is sufficiently explained by three causal paths. None of these are identical to the paths that explain the presence of radical change, and all three paths involve the absence of a high tech strategy. Overall, the findings do not contradict the conclusions we drew for our propositions.

In fs/QCA the calibration of raw values into set membership values is a crucial step. The calibration for three conditions, namely numerical flexibility, high tech strategy, and production flexibility, included a fuzzy value marginally below the critical threshold of 0.5 . We switched those values from 0.49999 to 0.50001 , marginally above the critical threshold, and repeated the analysis of sufficient conditions of radical change (see Table A3 in the appendix). Now seven (rather than five) causal paths are found to be sufficient for radical change. The paths I to IV are identical to our original solution in Table 3, and path V only differs in one condition. The new causal paths VI and VII have unique coverage rates of 0 , thus failing to yield additional insights over the causal paths we derived already. Hence, even moving values for three conditions across the critical threshold leaves our conclusions concerning the propositions intact. This is in line with the finding, observed in other studies, that slight changes in calibration do not alter the results substantially (Schneider and Wagemann 2012).

Finally, we examined whether the causal paths were each represented by certain industries, which would indicate industry-specific combinations. None of the paths, however, was represented by ideal type cases from one industry only. Hence, our findings can be interpreted as generic HR configurations that will be found to be conducive to radical change in a broad range of industries.

\section{Discussion}

\subsection{Main findings and implications}

The most striking finding in our analysis was the almost universal importance of functional flexibility. This is surprising given the traditional $\mathrm{VoC}$ approach, but it is not at odds with empirical evidence at the firm level (Zhou et al. 2011). Four paths which we found to be sufficient conditions for radical change (I, II, III, and IV) include functional flexibility. Furthermore, three paths (II, III, and IV) include the absence of a high share of academic personnel, and two paths (III and V) the absence of numerical flexibility. Apparently, subsidiaries of US MNEs in Europe often achieve radical change not through numerical flexibility and a high share of academic personnel but rather through functional 
flexibility. This pattern clearly contradicts the home country effect we argued in Proposition 1. Though partly compatible with a revised version of Proposition 2, it is also at odds with the host country effect argued in Proposition 2: Functional flexibility is also an important feature of HR practices in subsidiaries in the UK, which is an LME in which subsidiaries should follow the US model more closely.

According to our findings, functional flexibility is compatible with rather different patterns of causal conditions, indicating equifinality. For example, functional flexibility was successfully combined with a high tech strategy (Paths I and II), contradicting the dichotomous view of innovation propagated by the VoC approach (Hall and Soskice 2001) and the view that functional flexibility should be combined with production flexibility (Pull 2003). Similarly, functional flexibility was successfully combined with numerical flexibility (Path IV) though the HR literature tends to portray the two as alternative if not incompatible types of flexibility (Giannetti and Madia 2013).

More generally, the range of causal paths that sufficiently explain radical change emphasize that MNEs hold considerable leeway in different institutional settings (Lange 2009). The range of causal paths we found also resonates well with arguments that criticize the $\mathrm{VoC}$ approach because of a dichotomous picture of the innovation process and its juxtaposition of country and company models (Allen 2004; Crouch 2005; Peck and Theodore 2007; Akkermans, Castaldi and Los 2009).

\subsection{Limitations and routes for further research}

Although the data on 69 US-subsidiaries located in Germany, Switzerland, and the UK are fully appropriate for our research focus, it also has some limitations. The survey's response rate of about 7 percent is below the usual 10-12 percent response rate for surveys sent to CEOs (at least in the U.S.) (Geletkanycz 1997; Fiss 2011). Although the non-response bias cannot be fully avoided, the representativeness of the sample does not limit the validity of the results of a QCA in the same way that it would in regression analyses. This is due to the following three reasons (Fiss 2011): We are not interested in representative figures for entire sectors or countries but instead in the answers to general questions of which flexibility types are related to radical change and whether these configurations are country-specific or not. Therefore, the over- or under-representation of certain sectors or company sizes due to response biases would not change the validity of the findings. Furthermore, non-random samples are common in studies that analyze basic research questions (Doty, Glick and Huber 1993; Fiss 2011), therefore suggesting that fully representative samples are not the most essential factor for those kinds of questions. Finally, in contrast to regression analyses, the fuzzy set QCA method does not rely on a random sample drawn from a given distribution (Fiss 2011).

Our analysis suggests important routes for future research both for the study of international business from the VoC perspective and for the institutional theory of MNEs. In the VoC perspective, each vari- 
ety of capitalism form favors different types of HR flexibility. Since our findings point to the key importance of functional flexibility, and the European learning model more generally, future studies might explore more fully the HR practices linked to functional flexibility. Cues on which practices may be related to radical innovation are provided by the HR literature on flexibility and innovation (Minbaeva et al. 2003; Arvanitis 2005; Chang, Gong, Way and Jia 2012) and by recent accounts of organizational learning (Lorenz and Valeyre 2005; Jensen et al. 2007). Accordingly, practices of additional interest might be team work, employee suggestion schemes, and training practices.

The latter literature might also be tapped to explore whether functional and numerical flexibility are complements rather than substitutes. The VoC suggests, and we have argued in Proposition 1, that numerical and functional flexibility are alternatives. Recent evidence suggests, however, that DUI (Doing, Using, and Interacting) and STI (Science, Technology and Innovation) learning are complementary, with firms being more productive when combining both modes of learning (Jensen et al. 2007). Though the modes of learning are not identical to the types of flexibility we distinguished, they are clearly related. Functional flexibility overlaps with the more in-house type of DUI learning, whereas numerical flexibility (and the employment of academics) overlaps with the more outwardreaching type of STI learning.

Our analysis also suggests some routes of future research with reference to the institutional analysis of MNEs. In contrast to the previous literature on subsidiaries and their institutional environment, we studied not the transfer of practices but rather performance, in particular radical innovation. This approach has proven instructive but it deserves further exploration. Our measure of radical innovation was created based on two self-reported items relating to the frequency and the severity of business changes. Additional measures of innovative performance may be related to new products, new processes, or patenting activity (Taylor 2004; Akkermans et al. 2009; Allen 2013;). Analyzing such additional measures would be interesting especially to explore whether functional flexibility can help explain innovative performance more generally.

The sample we used consisted of subsidiaries. In future studies it might be instructive to include a reference group of indigenous firms, a research design frequently pursued in the study of the transfer of practices (Schmitt and Sadowski 2003; Iseke and Schneider 2012) and suggested in the VoC literature (Kristensen and Morgan 2012; Allen 2013). Including such a reference group of firms would help to clarify whether the variety of paths which we found to lead to radical change is a particularity of the more footloose MNEs or a finding that generalizes to all firms. Including headquarters in the US as a further reference group would allow us to infer more directly home and host country effects, and instances of how MNEs strategically tap the institutional resources of their host countries, termed 'institutional arbitrage' or 'institutional outsourcing' (Allen 2013). 


\section{Conclusion}

In this study, we provide novel results on the HR practices that subsidiaries of MNEs choose in differing varieties of capitalism countries in order to achieve radical innovations. An analysis of a fairly large sample of 69 US-subsidiaries located in Germany, Switzerland, and the UK has helped to uncover generic patterns previously overlooked in industry-level studies. In particular, the subsidiaries of US MNEs in the selected industries in Germany, Switzerland, and the UK apparently achieve radical innovations not only through numerical flexibility and a high share of academic personnel but rather through functional flexibility. The fuzzy-set qualitative comparative analysis has uncovered five HR combinations that are compatible with radical innovations in the form of major changes in products or services. As this implies, home and host country effects are much weaker than the VoC and the institutional theory of MNEs imply. The almost universal importance of functional flexibility - assigning workers to a variety of tasks - is surprising and deserves further analysis.

\section{References}

Akkermans, D., Castaldi, C., and Los, B. (2009), 'Do "liberal market economies" really innovate more radically than "coordinated market economies"? : Hall and Soskice reconsidered', Research Policy, 38(1), 181-191.

Allen, M. (2004), 'The varieties of capitalism paradigm. Not enough variety?', Socio-Economic Review, 2(1), 87-108.

Allen, M. M. C. (2013), 'Comparative capitalisms and the institutional embeddedness of innovative capabilities', Socio-Economic Review, 11(4), 771-794.

Allen, M. M. C., and Aldred, M. L. (2011), 'Varieties of capitalism, governance, and high-tech export performance: A fuzzy-set analysis of the new EU member states', Employee Relations, 33(4), 334 355.

Arundel, A., Lorenz, E., Lundvall, B.-A., and Valeyre, A. (2007), 'How Europe's economies learn. A comparison of work organization and innovation mode for the EU-15', Industrial and Corporate Change, 16(6), 1175-1210.

Arvanitis, S. (2005), 'Modes of labor flexibility at firm level: Are there any implications for performance and innovation? Evidence for the Swiss economy', Industrial and Corporate Change, 14(6), 993-1016.

Atkinson, J. (1984), 'Manpower strategies for flexible organizations', Personnel Management, 28-31.

Bamber, G., Lansbury, R. D., and Wailes, N. (Eds) (2011), International and comparative employment relations. Globalisation and change, Los Angeles, London: Sage.

Bassanini, A., and Ernst, E. (2002), 'Labour market regulation, industrial relations and technological regimes. A tale of comparative advantage', Industrial and Corporate Change, 11(3), 391-426.

Bouncken, R. B., Lehmann, C., and Ratzmann, M. (2013): 'Shades of gray: effect of external work arrangements on firm performance under operational and strategic contingencies', Journal of Business Economis, 83(8), 863-900

Brewster, C., Wood, G., and Brookes, M. (2006), 'Varieties of capitalism and varieties of firm', In G. Wood \& P. James (Eds), Institutions, Production, and Working Life, 217-234, Oxford: Oxford University Press.

Bureau van Dijk (Ed). (2009), Amadeus, Amsterdam: Bureau van Dijk.

Cappelli, P., and Neumark, D. (2004), 'External Churning and Internal Flexibility: Evidence on the Functional Flexibility and Core-Periphery Hypotheses', Industrial Relations: A Journal of Economy and Society, 43(1), 148-182.

Casper, S. (2007), Creating Silicon Valley in Europe. Public policy towards new technology industries, Oxford, New York: Oxford University Press. 
Cavusgil, S. T., and Cavusgil, E. (2012), 'Reflections on international marketing: destructive regeneration and multinational firms', Journal of the Academy of Marketing Science, 40(2), 202-217.

Chang, S., Gong, Y., Way, S. A., and Jia, L. (2012), 'Flexibility-Oriented HRM Systems, Absorptive Capacity, and Market Responsiveness and Firm Innovativeness', Journal of Management.

Ciabuschi, F., Forsgren, M., and Guy, F. (2011), 'Rationality vs ignorance: The role of MNE headquarters in subsidiaries' innovation processes', Journal of International Business Studies, 42(7), 958-970.

Crilly, D. (2010), 'Predicting stakeholder orientation in the multinational enterprise: A mid-range theory', Journal of International Business Studies, 42(5), 694-717.

Crouch, C. (2005), 'Models of capitalism', New Political Economy, 10(4), 339-456.

Doty, D. H., Glick, W. H., and Huber, G. P. (1993), 'Fit, equifinality, and organizational effectiveness: A test of two configurational theories', Academy of Management Journal, 1196-1250.

Estevez-Abe, M., Iversen, T., and Soskice, D. (2001), 'Social protection and the formation of skills: a reinterpretation of the welfare state', Varieties of capitalism: The institutional foundations of comparative advantage, 145-183.

Farndale, E., Brewster, C., and Poutsma, E. (2008), 'Coordinated vs. liberal market HRM: the impact of institutionalization on multinational firms', The International Journal of Human Resource Management, 19(11), 2004-2023.

Fenton-O'Creevy, M., Gooderham, P., and Nordhaug, O. (2007), 'Human resource management in US subsidiaries in Europe and Australia: centralisation or autonomy?', Journal of International Business Studies, 39(1), 151-166.

Fiss, P. C. (2007), 'A set-theoretic approach to organizational configurations', Academy of Management Review, 32(4), 1190-1198.

Fiss, P. C. (2011), 'Building Better Causal Theories: A Fuzzy Set Approach to Typologies in Organization Research', Academy of Management Journal, 54(2), 393-420.

Flickinger, M., Gruber-Mücke, T., and Fiedler, M. (2013), 'The linkage between human resource practices and organizational ambidexterity: An analysis of internal labor market dynamics in a port-ofentry context', Journal of Business Economics, 83(8), 923-946.

García-Castro, R., Aguilera, R. V., and Ariño, M. A. (2013), 'Bundles of Firm Corporate Governance Practices: A Fuzzy Set Analysis', Corporate Governance: An International Review.

Geletkanycz, M. A. (1997), 'The salience of 'culture's consequences': the effects of cultural values on top executive commitment to the status quo', Strategic Management Journal, 18(8), 615-634.

Giannetti, C., and Madia, M. (2013), 'Work arrangements and firm innovation: is there any relationship?', Cambridge Journal of Economics, 37(2), 273-297.

Greckhamer, T., Misangyi, V. F., Elms, H., and Lacey, R. (2008), 'Using qualitative comparative analysis in strategic management research. An examination of combinations of industry, corporate, and business-unit effects', Organizational Research Methods, 11(4), 695-726.

Gresov, C., and Drazin, R. (1997), 'Equifinality: Functional equivalence in organization design', Academy of Management Review, 403-428.

Hall, P. A., and Soskice, D. (2001), 'An Introduction to Varieties of Capitalism', In P. A. Hall \& D. Soskice (Eds), Varieties of Capitalism. The Institutional Foundations of Comparative Advantage, 1-68, Oxford: Oxford University Press.

Heidenreich, M. (2012), 'The social embeddedness of multinational companies: a literature review', Socio-Economic Review, 10(3), 549-579.

Henisz, W. J. (2000), 'The institutional environment for multinational investment', Journal of Law, Economics, and Organization, 16(2), 334-364.

Henisz, W., and Swaminathan, A. (2008), 'Institutions and international business', Journal of International Business Studies, 39(4), 537-539.

Herrmann, A. M., and Peine, A. (2011), 'When 'national innovation system' meet 'varieties of capitalism' arguments on labour qualifications: On the skill types and scientific knowledge needed for radical and incremental product innovations', Research Policy, 40(5), 687-701.

Iseke, A., and Schneider, M. (2012), 'Transfer of Employment Practices, Varieties of Capitalism, and National Employment Systems', A Review, Industrielle Beziehungen-Zeitschrift fuer Arbeit, Organisation und Management-The German Journal of Industrial Relations, 19(2), 236-252.

Jackson, G. (2005), 'Employee representation in the board compared. A fuzzy sets analysis of corpo- 
rate governance, unionism and political institutions', Industrielle Beziehungen, 12(3), 252-279.

Jackson, G., and Deeg, R. (2008), 'Comparing capitalisms: Understanding institutional diversity and its implications for international business', Journal of International Business Studies, 39(4), 540561.

Jackson, G., and Miyajima, H. (2007), Varieties of Capitalism, Varieties of Markets. Mergers and Acquisitions in Japan, Germany, France, the UK and USA.

Jensen, M. B., Johnson, B., Lorenz, E., and Lundvall, B. A. (2007), 'Forms of knowledge and modes of innovation', Research Policy, 36(5), 680-693.

Kalleberg, A. L. (2001), 'Organizing Flexibility: The Flexible Firm in a New Century', British Journal of Industrial Relations, 39(4), 479-504.

Kluike, M., and Pull, K. (2013), 'Similar, but still different: how US multinational companies in Germany and Switzerland use host-country training and skill practices', Industrial Relations Journal, 44(5-6), 495-513.

Kristensen, P. H., and Morgan, G. (2012), 'Theoretical Contexts and Conceptual Frames for the Study of Twenty-First Century Capitalisms', In G. Morgan \& R. Whitley (Eds), Capitalisms and Capitalism in the Twenty-First Century, 11-45: OUP Oxford.

Lange, K. (2009), 'Institutional embeddedness and the strategic leeway of actors: the case of the German therapeutical biotech industry', Socio-Economic Review, 7(2), 181-207.

Latzer, M. (2009), 'Information and communication technology innovations: radical and disruptive?', New Media \& Society, 11(4), 599-619.

Lazonick, W. (2010), 'The Chandlerian corporation and the theory of innovative enterprise', Industrial and Corporate Change, 19(2), 317-349.

Lorenz, E. (2011), 'Do labour markets and educational and training systems matter for innovation outcomes? A multi-level analysis for the EU-27', Science and Public Policy, 38(9), 691-702.

Lorenz, E., and Valeyre, A. (2005), 'Organisational Innovation, Human Resource Management and Labour Market Structure: A Comparison of the EU-15', Journal of Industrial Relations, 47(4), 424442.

Marsden, D. (1999), A theory of employment systems: micro-foundations of societal diversity: Oxford University Press, USA.

Marsden, D. (2000), 'A theory of job regulation, the employment relationship, and the organisation of labour institutions', Industrielle Beziehungen, 7(4), 320-347.

Marx, A. (2010), 'Crisp-set qualitative comparative analysis (csQCA) and model specification: Benchmarks for future csQCA applications', International Journal of Multiple Research Approaches, 4(2), 138-158.

Meuer, J., Rupietta, C., Backes-Gellner, U. (2015), 'Layers of co-existing innovation systems', Research Policy, 44(4): 888-910.

Meyer, A. D., Tsui, A. S., and Hinings, C. R. (1993), 'Configurational approaches to organizational analysis', Academy of Management Journal, 36(6), 1175-1195.

Minbaeva, D., Pedersen, T., Björkman, I., Fey, C. F., and Park, H. J. (2003), 'MNC knowledge transfer, subsidiary absorptive capacity, and HRM', Journal of International Business Studies, 34(6), 586-599.

Pajunen, K. (2008), 'Institutions and inflows of foreign direct investment. A fuzzy-set analysis', Journal of International Business Studies, 39(4), 652-669.

Parry, E., Dickmann, M., and Morley, M. (2008), 'North American MNCs and their HR policies in liberal and coordinated market economies', The International Journal of Human Resource Management, 19(11), 2024-2040.

Peck, J., and Theodore, N. (2007), 'Variegated capitalism', Progress in Human Geography, 31(6), 731-772.

Porter, M. E. (1990), The competitive advantage of nations. New York: The Free Press.

Pudelko, M., and Harzing, A. (2007), 'Country-of-origin, localization, or dominance effect? An empirical investigation of HRM practices in foreign subsidiaries', Human Resource Management, 46(4), 535-559.

Pull, K. (2003), 'Managerial flexibility and the comparative attractiveness of the UK as a business location', European Business Journal, 15(2), 49-60.

Pull, K. (2008), 'Flexibility in HRM and foreign direct investment: Do international investors self- 
select?', International Journal of Human Resource Management, 19(2), 314-329.

Ragin, C. C. (1987), The comparative method. Moving beyond qualitative and quantitative strategies, Berkeley, Los Angeles, London: University of California Press.

Ragin, C. C. (2000), Fuzzy-set social sciences, Chicago: University of Chicago Press.

Ragin, C. C. (2006), 'Set relations in social research. Evaluating their consistency and coverage', Political Analysis, 14(3), 291-310.

Ragin, C. C. (2008), Redesigning social inquiry. Fuzzy sets and beyond, Chicago: University of Chicago Press.

Ragin, C. C., and Fiss, P.C. (2008), 'Net effects analysis versus configurational analysis: An empirical demonstration. In C. C. Ragin (Ed.), Redesigning social inquiry: Fuzzy sets and beyond: 190-212. Chicago: University of Chicago Press.

Ragin, C. C., and Strand, S. I. (2008), 'Using qualitative comparative analysis to study causal order. Comment on Caren and Panofsky (2005)', Sociological Methods and Research, 36(4), 431-441.

Ragin, C., and Davey, S. (2009), fs/QCA, Version 2.5, Tucson: University of Arizony.

Rihoux, B., and Ragin, C. (2009), Configurational comparative methods. Qualitative comparative analysis (QCA) and related techniques, Thousand Oaks, New Delhi, London, Singapore: Sage.

Schmitt, M., and Sadowski, D. (2003), 'A cost-minimization approach to the international transfer of HRM/IR practices. Anglo-Saxon multinationals in the Federal Republic of Germany', International Journal of Human Resource Management, 14(3), 409-430.

Schneider, C. Q., and Wagemann, C. (2012), Set-theoretic methods for the social sciences. A guide to qualitative comparative analysis, Cambridge: Cambridge University Press.

Schneider, M. R., and Paunescu, M. (2012), 'Changing varieties of capitalism and revealed comparative advantages from 1990 to 2005: a test of the Hall and Soskice claims', Socio-Economic Review, 10(4), 731-753.

Schneider, M. R., Schulze-Bentrop, C., and Paunescu, M. (2010), 'Mapping the institutional capital of high-tech firms. A fuzzy-set analysis of capitalist variety and export performance', Journal of International Business Studies, 41, 246-266.

Schulze-Bentrop, C. (2013), Qualitative comparative analysis (QCA) and configurational thinking in management studies, Frankfurt, M: PL Acad. Research.

Taylor, M. Z. (2004), 'Empirical Evidence Against Varieties of Capitalism's Theory of Technological Innovation', International Organization, 58(Summer), 601-631.

Teuber, Silvia (2012) The effect of vocational education and labor market institutions on personnel and organizational strategies - an international comparison. Zürich: e-Diss. 2012.

Valverde, M., Tregaskis, O., and Brewster, C. (2000), 'Labor flexibility and firm performance', International advances in economic research, 6(4), 649-661.

Wilkens, U. Ruiner, C., and Küpper, M. (2013), 'Flexible arrangements with the highly qualified workforce: antecedents and effects of different contract policies in knowledge-intensive firms', Journal of Business Economics, 83(8), 837-861.

Witcher, B. J., and Chau, V. S. (2012), 'Varieties of Capitalism and Strategic Management: Managing Performance in Multinationals after the Global Financial Crisis', British Journal of Management, 23, S58.

Witt, M. A., and Lewin, A. Y. (2007), 'Outword foreign direct investment as escape response to home country institutional constraints', Journal of International Business Studies, 38(4), 579-594.

Zhou, H., Dekker, R., and Kleinknecht, A. (2011), 'Flexible labor and innovation performance: evidence from longitudinal firm-level data', Industrial and Corporate Change, 20(3), 941-968. 


\section{Appendix}

Table A1. Enlarged truth table for radical change (outcome) and five causal conditions

\begin{tabular}{|c|c|c|c|c|c|c|}
\hline $\begin{array}{l}\text { Academic } \\
\text { personnel }\end{array}$ & $\begin{array}{l}\text { Numerical } \\
\text { flexibility }\end{array}$ & $\begin{array}{l}\text { Functional } \\
\text { flexibility }\end{array}$ & $\begin{array}{l}\text { High tech } \\
\text { strategy }\end{array}$ & $\begin{array}{l}\text { Production } \\
\text { flexibility }\end{array}$ & $\mathrm{N}$ & Consistency \\
\hline 0 & 1 & 1 & 1 & 1 & 2 & 0.889 \\
\hline 1 & 1 & 1 & 1 & 0 & 3 & 0.883 \\
\hline 1 & 0 & 1 & 1 & 0 & 4 & 0.875 \\
\hline 0 & 1 & 1 & 1 & 0 & 6 & 0.832 \\
\hline 0 & 0 & 1 & 1 & 0 & 5 & 0.829 \\
\hline 0 & 0 & 1 & 1 & 1 & 1 & 0.824 \\
\hline 1 & 0 & 0 & 1 & 1 & 2 & 0.810 \\
\hline 0 & 1 & 1 & 0 & 1 & 3 & 0.808 \\
\hline 0 & 0 & 1 & 0 & 0 & 2 & 0.805 \\
\hline 1 & 1 & 1 & 0 & 1 & 2 & 0.796 \\
\hline 0 & 0 & 0 & 1 & 0 & 1 & 0.794 \\
\hline 1 & 1 & 1 & 0 & 0 & 3 & 0.780 \\
\hline 1 & 0 & 1 & 0 & 0 & 6 & 0.766 \\
\hline 0 & 0 & 1 & 0 & 1 & 2 & 0.730 \\
\hline 0 & 0 & 0 & 0 & 0 & 3 & 0.716 \\
\hline 1 & 1 & 0 & 0 & 1 & 2 & 0.713 \\
\hline 0 & 1 & 0 & 1 & 0 & 2 & 0.711 \\
\hline 0 & 1 & 0 & 0 & 1 & 1 & 0.697 \\
\hline 1 & 0 & 0 & 0 & 0 & 2 & 0.689 \\
\hline 1 & 0 & 0 & 1 & 0 & 1 & 0.679 \\
\hline 1 & 1 & 0 & 0 & 0 & 4 & 0.676 \\
\hline 0 & 1 & 1 & 0 & 0 & 8 & 0.658 \\
\hline 0 & 1 & 0 & 0 & 0 & 4 & 0.658 \\
\hline 1 & 0 & 0 & 0 & 1 & 2 & 0.618 \\
\hline
\end{tabular}

$\mathrm{N}$ : number of cases

Notes on the analysis:

- The five causal conditions we included imply 32 (25) possible ideal types. Out of these, we observe 23 or $72 \%$. As this implies, the so-called limited diversity is not a problem in our data.

- All individual conditions and their negation were analyzed for their necessity. None of the single conditions achieved the critical consistency score of 0.9 .

- The analysis of sufficiency was conducted with a standard 0.80 consistency cutoff (see Table 3 in the text for further details). 
Table A2. Sufficient conditions for negation of radical change

\begin{tabular}{|c|c|c|c|}
\hline \multirow[b]{2}{*}{ Conditions } & \multicolumn{3}{|c|}{$\begin{array}{l}\text { Outcome: Negation of radi- } \\
\text { cal change } \\
\text { Causal path }\end{array}$} \\
\hline & I & II & III \\
\hline Academic personnel & $\otimes$ & $\bullet$ & $\otimes$ \\
\hline Numerical flexibility & $\bullet$ & $\otimes$ & $\otimes$ \\
\hline Functional flexibility & & $\otimes$ & $\bullet$ \\
\hline High tech strategy & $\otimes$ & $\otimes$ & $\otimes$ \\
\hline Production flexibility & $\otimes$ & $\bullet$ & $\bullet$ \\
\hline Consistency & 0.83 & 0.86 & 0.83 \\
\hline Raw coverage & 0.35 & 0.12 & 0.14 \\
\hline Unique coverage & 0.23 & 0.07 & 0.04 \\
\hline Overall solution consistency & & & 0.85 \\
\hline Overall solution coverage & & & 0.46 \\
\hline
\end{tabular}

The complex solution is reported.

Source: Own data, calculations with fs/QCA, Version 2.5 (Ragin and Davey 2009)

Table A3. Sufficient conditions for radical change with alternative calibration

\begin{tabular}{|c|c|c|c|c|c|c|c|}
\hline \multirow[b]{3}{*}{ Conditions } & \multirow[b]{3}{*}{1} & \multicolumn{6}{|c|}{ Outcome: Radical change } \\
\hline & & \multicolumn{6}{|c|}{ Causal path } \\
\hline & & II & III & IV & V & VI & VII \\
\hline Academic personnel & & $\otimes$ & $\otimes$ & $\otimes$ & $\bullet$ & & $\bullet$ \\
\hline Numerical flexibility & & & $\otimes$ & $\bullet$ & & $\bullet$ & $\bullet$ \\
\hline Functional flexibility & $\bullet$ & $\bullet$ & $\bullet$ & $\bullet$ & $\otimes$ & $\bullet$ & \\
\hline High tech strategy & $\bullet$ & - & & & $\bullet$ & $\bullet$ & $\bullet$ \\
\hline Production flexibility & $\otimes$ & & $\otimes$ & $\bullet$ & $\bullet$ & & $\bullet$ \\
\hline Consistency & 0.82 & 0.79 & 0.83 & 0.84 & 0.86 & 0.81 & 0.83 \\
\hline Raw coverage & 0.46 & 0.39 & 0.26 & 0.28 & 0.18 & 0.44 & 0.18 \\
\hline Unique coverage & 0.02 & 0.02 & 0.03 & 0.03 & 0.03 & 0.00 & 0.00 \\
\hline Overall solution consistency & & & & & & & 0.79 \\
\hline Overall solution coverage & & & & & & & 0.69 \\
\hline
\end{tabular}

The complex solution is reported.

Note: For numerical flexibility, high tech strategy, and production flexibility, an alternative calibration was used by substituting 0.5001 for 0.4999 .

Source: Own data, calculations with fs/QCA, Version 2.5 (Ragin and Davey 2009) 


\section{Figures and Tables for text}

\section{Figure 1: Explanatory Model}

\begin{tabular}{|c|c|c|c|c|c|c|}
\hline $\begin{array}{l}\text { Numerical Flexi- } \\
\text { bility }\end{array}$ & \multirow{2}{*}{$*$} & $\begin{array}{c}\text { High share of academic } \\
\text { personnel }\end{array}$ & \multirow{2}{*}{$*$} & $\begin{array}{l}\text { High tech } \\
\text { strategy }\end{array}$ & \multirow{2}{*}{$\Rightarrow$} & $\begin{array}{c}\text { Radical Innovation } \\
\text { (home country effect) }\end{array}$ \\
\hline $\begin{array}{l}\text { Functional flexi- } \\
\text { blity }\end{array}$ & & $\begin{array}{c}\text { Low share of academic } \\
\text { personnel }\end{array}$ & & $\begin{array}{l}\text { Production } \\
\text { flexibility }\end{array}$ & & $\begin{array}{l}\text { Radical Innovation } \\
\text { (host country effect) }\end{array}$ \\
\hline
\end{tabular}

Notes: * denotes a logical 'and'

Table 1. Calibration of outcome variable 'radical innovation'

\begin{tabular}{|c|c|c|}
\hline \multicolumn{2}{|c|}{ Raw values } & \multicolumn{2}{|c|}{ Fuzzy-set values } \\
\hline Importance of core changes (values) & Frequency of core changes (categories) \\
\hline $5 \& 4$ & $1-3$ years & 1 'full membership' \\
\hline $5 \& 4$ & $4-6$ years & 0.8 \\
\hline $5 \& 4$ & $7+$ years & 0.6 \\
\hline $1-3$ & $1-3$ years & 0.4 \\
\hline $1-3$ & $4-6$ years & 0.2 \\
\hline $1-3$ & $7+$ years & 0 'full non-membership' \\
\hline
\end{tabular}

Table 2. Calibration of causal conditions

\begin{tabular}{|c|c|c|}
\hline Condition & Raw value & Fuzzy-set value \\
\hline \multirow{3}{*}{ Academic personnel } & $90 \%$ & 0.99 \\
\hline & $50 \%$ & 0.5001 \\
\hline & $10 \%$ & 0.01 \\
\hline \multirow{5}{*}{ Numerical flexibility } & 5 & 1 \\
\hline & 4 & 0.75 \\
\hline & 3 & 0.4999 \\
\hline & 2 & 0.25 \\
\hline & 1 & 0 \\
\hline \multirow{5}{*}{ Functional flexibility } & 5 & 1 \\
\hline & 4 & 0.66 \\
\hline & 3 & 0.33 \\
\hline & 2 & 0 \\
\hline & 1 & 0 \\
\hline \multirow{5}{*}{ High tech strategy } & 5 & 1 \\
\hline & 4 & 0.75 \\
\hline & 3 & 0.4999 \\
\hline & 2 & 0.25 \\
\hline & 1 & 0 \\
\hline \multirow{5}{*}{ Production flexibility } & 5 & 1 \\
\hline & 4 & 0.75 \\
\hline & 3 & 0.4999 \\
\hline & 2 & 0.25 \\
\hline & 1 & 0 \\
\hline
\end{tabular}


Table 3. Sufficient conditions for radical innovation

\begin{tabular}{|c|c|c|c|c|c|c|c|}
\hline \multirow[b]{2}{*}{ Conditions } & \multicolumn{5}{|c|}{ Outcome: Radical innovation } & \multicolumn{2}{|c|}{$\begin{array}{c}\text { Theoretical causal } \\
\text { path }\end{array}$} \\
\hline & 1 & II & III & IV & V & Prop. 1 & Prop. 2 \\
\hline Academic personnel & & $\otimes$ & $\otimes$ & $\otimes$ & $\bullet$ & $\bullet$ & $\otimes$ \\
\hline Numerical flexibility & & & $\otimes$ & $\bullet$ & $\otimes$ & $\bullet$ & \\
\hline Functional flexibility & $\bullet$ & • & $\bullet$ & $\bullet$ & $\otimes$ & & $\bullet$ \\
\hline High tech strategy & $\bullet$ & • & & & $\bullet$ & $\bullet$ & \\
\hline Production flexibility & $\otimes$ & & $\otimes$ & $\bullet$ & $\bullet$ & & $\bullet$ \\
\hline Number of ideal type cases & 16 & 14 & 7 & 5 & 2 & & \\
\hline in UK & 4 & 2 & 2 & 2 & 1 & & \\
\hline in Switzerland & 6 & 6 & 2 & 1 & 1 & & \\
\hline in Germany & 6 & 6 & 3 & 2 & 0 & & \\
\hline Consistency & 0.82 & 0.79 & 0.83 & 0.84 & 0.81 & & \\
\hline Raw coverage & 0.46 & 0.39 & 0.26 & 0.28 & 0.12 & & \\
\hline Unique coverage & 0.12 & 0.03 & 0.03 & 0.03 & 0.39 & & \\
\hline Overall solution consistency & & & & & 0.78 & & \\
\hline Overall solution coverage & & & & & 0.65 & & \\
\hline
\end{tabular}

- : Causal condition is present (above 0.5 )

$\otimes$ : Causal condition is absent (below 0.5)

The complex solution is reported.

Notes on the quality of findings:

- The solution consistency denotes the degree to which cases for the solutions we find really have an outcome membership score which is higher than the membership score of the solution terms (the condition for a sufficient condition). The solution consistency has an intuition comparable to the significance level for a regression equation. The value of 0.78 is satistfactory in comparison with other studies.

- The coverage terms denote how much of the outcome is really explained by the solution terms. The coverage rate of the solution has an intuition comparable to an $\mathrm{R}^{2}$ in a regression analyse, the unique coverage rates have an intuition comparable to $\Delta \mathrm{R}^{2}$ in a regression analysis. A solution coverage rate of 0.65 is satistfactory in comparison with other studies.

- It can be excluded that our findings would occur with random data as our 69 cases by far exceed the 25 cases suggested as minimum given five conditions (Marx 2010). The combination of 69 cases and five conditions also complies with a formula indicating the most appropriate combination of sample size, number of conditions, and degree of limited diversity (Schulze-Bentrop 2013).

Source: Own data, calculations with fs/QCA, Version 2.5 (Ragin and Davey 2009) 